\title{
Role of selective pulmonary vasodilators in management of hypertensive ventricular septal defect in pediatrics
}

I.M.Kasab, M.E.Rezk, B.M.Aglan and M.A.Saleh

Cardiothoracic surgery, Dept., Faculty of Medicine, Benha Univ., Benha, Egypt

E-mail: salsa311987@gmail.com

\begin{abstract}
Background: Septal ventricular defect is an acyanotic heart condition that requires operation. Pulmonary artery pressure is a major determinant in the outcome of surgery Objectives: Evaluation of the usage of antihypertensive pulmonary medicines after surgical closure of septal ventricular hypertension defects. Materials: 60 patients were chosen for primary ventricular septal defect surgical repair. Instances with congenital abnormalities were eliminated rather than PDA or ASD and redo cases. These cases were divided into two groups (each of 30 patients) one with oral sildenafil and the other with no oral sildenafil. Results: The mean pulmonary artery pressure of sildenafil dropped from $66.4 \pm 9.1$ to $42.5 \pm 3.6 \mathrm{mmHg}$ and decreased to $50.2 \pm 5.3 \mathrm{mmHg}$ in the control group. Conclusion: Pulmonary antihypertensive medicines have an essential role in reducing pulmonary artery pressure and provide improved surgical outcomes.
\end{abstract}

Keywords: Ventricular septal defect, pulmonary hypertension, pulmonary vasodilators

\section{Introduction}

Pulmonary hypertension and lung hypertension crises are major consequences after the hypertensive ventricular septal pharmacological closure.

The results of VSD closures will rely on changes in the closure of these abnormalities in individuals diagnosed with VSD and PAH. In these individuals with PAH the morbidity and mortality of the VSD closure remained significant. The most frequent cause of postoperative death have been pulmonary hypertensive crisis, right ventricular failure and respiratory failure. [1]

Although in surgically advanced nations individuals with big VSDs and high PVR are seldom encountered, they nevertheless constitute a significant share of the population with congenital heart diseases in poor countries. Delayed presentation and surgery are not uncommon in the developing world for individuals with VSD and PAH. Severe pulmonary arterial hypertension (PAH) may lead to increased risk of morbidity and death in individuals with big ventricular septal defects (VSD) if the VSD is closed. [2]

If VSD is moderate to big and non-restrictive, the closure of VSDs is advised before the age of six months to avoid pulmonary vascular disease. Cardiac catheterization is suggested for measuring pulmonary vascular resistance and testing pulmonary vasoreactivity, in particular if the permanent increase in pulmonary vascular resistance is a clinical issue. [3]

This research examined the effect of pulmonary antihypertense medicines in the result of surgical closure of hypertensive septal ventricular medicines.

\section{Patients and Methods}

Sixty patients were selected from the cases came for primary surgical closure of ventricular septal defect. They were divided into 2 groups. The first group (control group) included 30 patients with pre-operative mean pulmonary artery pressure exceeding $50 \mathrm{mmHg}$ (severe pulmonary hypertension). This group includes 19 males and 11 females with male to female ratio 1.6:1. Their age ranged between 5 and 20 months with mean age of $12.9 \pm 5.69$ months. Their weight ranged between 4 and 14 Kilograms with mean weight of 8.56 $\pm 3.1 \mathrm{kgs}$. This group received as medication postoperative (Antifailure drugs only). The second group (sildenafil group) included 30 patients with preoperative mean pulmonary artery pressure exceeding $50 \mathrm{mmHg}$ (severe pulmonary hypertension). This group includes 16 males and 14 females with male to female ratio $1.4: 1$. Their age ranged between 5 and 24 months with mean age of $12 \pm 5.84$ months. Their weight ranged between 4.5 and 12 Kilograms with mean weight of $6.97 \pm 1.6 \mathrm{kgs}$. This group received as medication postoperative (Antifailure drugs \& Pulmonary antihypertensive drugs). In the postoperative period, all hemodynamic date were recorded. Also, we followed the time of mechanical ventilation, inotropes, vasodilators; pulmonary hypertensive crisis with its frequency, the period of ICU stay, the period of hospital stay, morbidity and mortality.

\section{Results}

In the control group, the age ranged between 5 and 20 months with mean age of $12.9 \pm 5.69$ months, their weight ranged between 4 and 14 Kilograms with mean weight of $8.56 \pm 3.1 \mathrm{kgs}$ and it included 19 males and 11 females with male to female ratio 1.6:1. While in the sildenafil group, the age ranged between 5 and 24 months with mean age of $12 \pm 5.84$ months, their weight ranged between 4.5 and 12 Kilograms with mean weight of $6.97 \pm 1.6 \mathrm{kgs}$ and it included 16 males and 14 females with male to female ratio 1.4:1 Table (1). 
The mean values of mean pulmonary artery pressure (PAP) of the two groups and pressure gradient across the VSD are shown in table 2. Comparative study between the two groups of patients regarding the mean pulmonary artery pressure was statistically nonsignificant with $\mathrm{P}$ value $>0.05$.

All cases of the two groups were operated under cardiopulmonary bypass. Myocardial protection was achieved by local cooling and coronary perfusion with cold cardioplegic solution. The external morphology of different cardiac chambers and pulmonary artery were inspected, the type and size of the VSDs were identified in all cases. Cases with tricuspid valve incompetence were tested after closure of the VSD. The total bypass time in group I ranged between 33 and 100 with mean of $52.81 \pm 8.51$ minutes. The ischemic time in group I ranged between 20 and 48 with mean of $33.08 \pm 5.3$ minutes. The total bypass time in group II ranged between 36 and 110 with mean of $56.26 \pm 8.81$ minutes. The ischemic time in group II ranged between 23 and 50 with mean of $35.24 \pm 5.68$ minutes. (Table 3)

Comparative study between the two groups of patients regarding the mean ischemic time was statistically non-significant $(\mathrm{P}$ value $>0.05)$. Regarding the total bypass time there was non-significant difference between the two groups with $(\mathrm{P}$ value $>$ $0.05)$.

None of our patients were extubated intraoperatively. All patients were transferred to the intensive care unit (ICU). These patients were mechanically ventilated for variable periods according to the clinical condition and blood gas analysis for each patient.

In group I, the time need for ventilation ranged between 6 and 120 hours with a mean of $35.58 \pm 22.69$ hours. 4 cases required ventilation for more than 48 hours, one patient had bad chest condition which required recurrent and prolonged ventilation then died, 5 cases developed pulmonary hypertensive crisis on ventilator and required administration of muscle relaxant and sedative. $\varepsilon$ patients of these died due to crisis.

In group II the time need for ventilation ranged between 5 and $9 \wedge$ hours with a mean of $\Upsilon^{0.56 \pm 11.33}$ hours. One patient developed ARDS and shock lung with failure of weaning from ventilation and died. 3 cases developed pulmonary hypertensive crisis on ventilator and required administration of muscle relaxant and sedative, one of them died due to crisis.

5 patients of Group I developed pulmonary hypertensive crisis (16.7\% of group I). 4 patients $(80 \%)$ of these 5 patients with postoperative pulmonary hypertensive crisis died during the postoperative period. 3 patients of Group II developed pulmonary hypertensive crisis (10\% of group II). 1 patient $(33 \%)$ of these 3 patients with postoperative pulmonary hypertensive crisis died during the postoperative period.

Table (1) age, sex and weight of both groups.

\begin{tabular}{llcc}
\hline & & Group I & Group II \\
\hline Age & Range & $5-20$ & $5-24$ \\
(Month) & Mean & $12.9 \pm 5.69$ & $12 \pm 5.84$ \\
Weight & Range & $4-14$ & $4.5-12$ \\
(kg) & Mean & $8.56 \pm 3.1$ & $6.97 \pm 1.6$ \\
Sex & Male & 19 & 16 \\
& Female & 11 & 14 \\
\hline
\end{tabular}

Table (2) Echo-cardiographic pressure measurements of the two groups.

\begin{tabular}{llllll}
\hline \multicolumn{2}{l}{ Echo-cardiographic pressure measurements } & $\begin{array}{l}\text { Group I } \\
\text { No of cases }\end{array}$ & \begin{tabular}{l} 
\% \\
\multicolumn{2}{l}{}
\end{tabular} & $\begin{array}{l}\text { Group II } \\
\text { No of cases }\end{array}$ & $\%$ \\
\hline Pressure gradient across & $\mathbf{> 6 0} \mathbf{~ m m H g}$ & 0 & 0 & 0 & 0 \\
VSD & $\mathbf{3 0}-\mathbf{6 0} \mathbf{~ m m H g}$ & 7 & 23 & 5 & 17 \\
& $<\mathbf{3 0} \mathbf{~ m m H g}$ & 23 & 77 & 25 & 83 \\
Mean pulmonary artery pressure & $59.2 \pm 9.5$ & & $66.4 \pm 9.1$ & \\
\hline
\end{tabular}

Table (3) Operative data of patients of the two groups.

\begin{tabular}{llcccc}
\hline \multicolumn{2}{l}{ Operative data } & \multicolumn{2}{c}{ Group I } & \multicolumn{2}{c}{ Group II } \\
\multicolumn{1}{l}{ No of cases } & \% & No of cases & \% \\
\hline Size of & Small (< Heggar 5) & 4 & 13.3 & 2 & 6.7 \\
VSD & Moderate (Heggar 5-10) & 25 & 83.3 & 26 & 86.7 \\
& Large (> Heggar 10) & 1 & 3.3 & 2 & 6.7 \\
Mean total bypass time + SD & $52.81 \pm 8.51$ & $56.26 \pm 8.81$ \\
Mean cross clamp time + SD & $33.08 \pm 5.3$ & \multicolumn{2}{c}{$35.24 \pm 5.68$} \\
\hline
\end{tabular}


The period of stay in the ICU for patients of group I, it ranged between 4 days and 20 days with a mean of $7.89 \pm 4.57$ days. In group II ranged between 2 days and 12 days with a mean of $4.69 \pm 2.1$ days. In The total period of stay in the hospital for patients of group I ranged between 9 and 27 days with a mean of $14.25 \pm$ 2.81 days. In group II, it ranged between 7 and 19 days with a mean of $10.35 \pm 4.88$ days. Table (4)

In group I, 16 patients $(53.3 \%)$ required Adrenaline at a dose of $100 \mathrm{ng} / \mathrm{kg} / \mathrm{min}, 8$ patients $(26.7 \%)$ required Adrenaline at a dose of $>100$ $\mathrm{ng} / \mathrm{kg} / \mathrm{min} .15$ patients $(50 \%)$ required Dobutamine at a dose of $10 \mathrm{ug} / \mathrm{kg} / \mathrm{min}, 9$ patients $(30 \%)$ at $>10$ $\mathrm{ug} / \mathrm{kg} / \mathrm{min}$. 10 patients $(33.3 \%)$ required Noradrenaline at a dose between 50 and $100 \mathrm{ng} / \mathrm{kg} / \mathrm{min} .10$ patients $(33.3 \%)$ required Milrinone at dose $0.5 \mathrm{ug} / \mathrm{kg} / \mathrm{min}$. 8 patients $(26.7 \%)$ required Lasix infusion at a dose of 1 $\mathrm{mg} / \mathrm{kg} / \mathrm{h}$.

In group II, 12 patients (40\%) required Adrenaline at a dose of $100 \mathrm{ng} / \mathrm{kg} / \mathrm{min}, 6$ patients $(20 \%)$ required Adrenaline at a dose of $>100 \mathrm{ng} / \mathrm{kg} / \mathrm{min} .13$ patients $(43.3 \%)$ required Dobutamine at a dose of 10 $\mathrm{ug} / \mathrm{kg} / \mathrm{min}, 6$ patients $(20 \%)$ at $>10 \mathrm{ug} / \mathrm{kg} / \mathrm{min}$. 5 patients $(16.6 \%)$ required Noradrenaline at a dose between 50 and $100 \mathrm{ng} / \mathrm{kg} / \mathrm{min} .5$ patients $(16.6 \%)$ required Milrinone at dose $0.5 \mathrm{ug} / \mathrm{kg} / \mathrm{min}$. 6 patients (20\%) required Lasix infusion at a dose of $1 \mathrm{mg} / \mathrm{kg} / \mathrm{h}$. table (5)

Comparative study between the two groups of patients regarding the need for Dobutamine was statistically significant $(\mathrm{P}$ value $<0.001$ )

Comparative study between the two groups of patients regarding the mean pulmonary artery pressure was statistically significant (P value $<0.001)$

In group I, 5 patients had chest infection, 3 patients with mild dyspnea and 2 patients with moderate dyspnea due to prolonged ventilation. 4 patients had superficial wound infection. Radiologically: There was mild increase in cardiothoracic ratio in 12 patients. 6 cases with dilated pulmonary artery shadow. Echocardiography: 5 patients had small residual VSD (2$3 \mathrm{ml}$ ), 6 cases had mild to moderate tricuspid regurge. 3 cases had severe tricuspid regurge.

In group II, 4 patients had chest infection, 4 patients with mild dyspnea. 2 patients had superficial wound infection. Radiologically: There was mild increase in cardiothoracic ratio in 9 patients. 4 cases with dilated pulmonary artery shadow. Echocardiography: 4 patients had small residual VSD (2$3 \mathrm{ml}$ ), 4 cases had mild to moderate tricuspid regurge. 2 cases had severe tricuspid regurge.

In group I, 5 patients died in the ICU, one of them died after 8 days due to bad chest condition which required recurrent and prolonged ventilation and the other 4 developed pulmonary hypertensive crisis. In group II, 2 patients died, one of them died after 12 days due to ARDS and shock lung with failure of weaning from ventilation, and the other patient developed pulmonary hypertensive crisis and died

We followed the patients after 6 months and found in group I, 7 patients had recurrent chest infection with grade I dyspnea. In group II, 3 patients had recurrent chest infection with grade I dyspnea. Radiologically, there was mild increase in cardiothoracic ratio in 8 patients. 12 cases with dilated pulmonary artery shadow. In group II, There was mild increase in cardiothoracic ratio in 5 patients. 8 cases with dilated pulmonary artery shadow.

Late Postoperative measurement of mean pulmonary artery pressure in group I \& group II in table (7)

Table (4) ventilation time, ICU \& hospital stay.

\begin{tabular}{llcc}
\hline & & Group I & Group II \\
\hline Ventilation time & Range & $6-120$ & $5-98$ \\
(hours) & Mean & $35.58 \pm 22.69$ & ro. $56 \pm 11.33$ \\
ICU stay (day) & Range & $4-20$ & $2-12$ \\
& Mean & $7.89 \pm 4.57$ & $4.69 \pm 2.1$ \\
Hospital stay & Range & $9-27$ & $7-19$ \\
(day) & Mean & $14.25 \pm 2.81$ & $10.35 \pm 4.88$ \\
\hline
\end{tabular}

Table (5) usage of cardiac support.

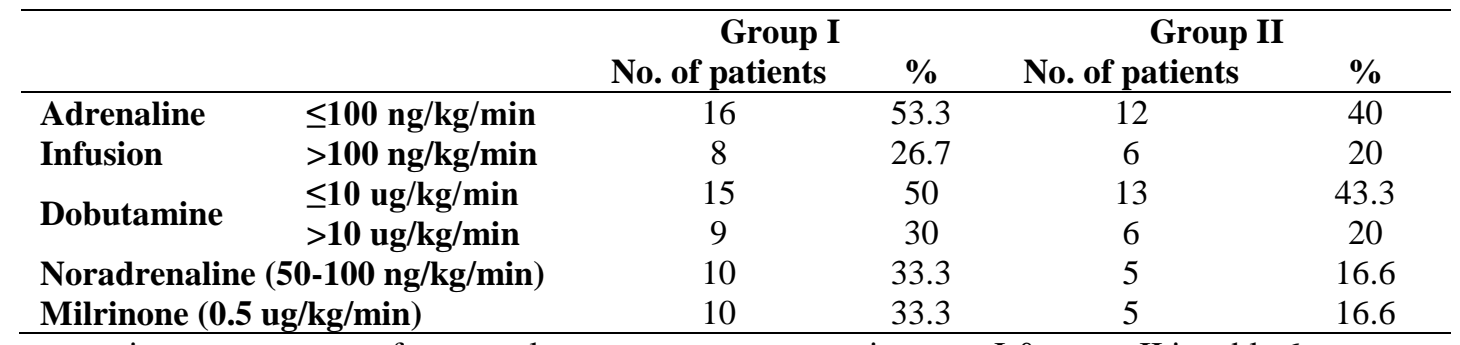

Early Postoperative measurement of mean pulmonary artery pressure in group I \& group II in table 6: 
Table (6) Early postoperative Echo-cardiographic pressure measurements of the two groups.

\begin{tabular}{llcccc}
\hline Echo-cardiographic pressure measurements & $\begin{array}{c}\text { Group I } \\
\text { No of cases }\end{array}$ & $\begin{array}{c}\text { Group II } \\
\text { No of cases }\end{array}$ & \% \\
\hline \multirow{3}{*}{ Mean PAP } & $<\mathbf{3 0} \mathbf{~ m m H g}$ & 3 & 10 & 4 & 13 \\
& $\mathbf{3 0}-\mathbf{5 0} \mathbf{~ m m H g}$ & 17 & 57 & 20 & 67 \\
& $>\mathbf{5 0} \mathbf{~ m m H g}$ & 10 & 33 & 6 & 20 \\
& & $50.2 \pm 5.3$ & \multicolumn{2}{c}{$42.5 \pm 3.6$} \\
\hline
\end{tabular}

Table (7) Late postoperative Echo-cardiographic pressure measurements of the two groups.

\begin{tabular}{llcccc}
\hline Echo-cardiographic pressure measurements & \multicolumn{2}{c}{ Group I } & \multicolumn{2}{c}{ Group II } \\
& No of cases & \% & No of cases & \% \\
\hline \multirow{3}{*}{ Mean PAP } & $<\mathbf{3 0} \mathbf{~ m m H g}$ & 12 & 50 & 20 & 71.5 \\
& $\mathbf{3 0}-\mathbf{5 0 ~} \mathbf{~ m m H g}$ & 8 & 33 & 6 & 21.5 \\
& $>\mathbf{5 0} \mathbf{~ m m H g}$ & 4 & 17 & 2 & 7 \\
& & $40.7 \pm 6.2$ & \multicolumn{2}{c}{$33.2 \pm 4.5$} & \\
\hline
\end{tabular}

Comparative study between the two groups of patients regarding the mean pulmonary artery pressure by was statistically significant $(\mathrm{P}$ value $<0.001)$.

Other Echo-cardiographic data: in group I, 2 patients had small residual VSD $(2 \mathrm{ml}) .5$ patients had residual pulmonary hypertension ranged between 30 and $65 \mathrm{mmHg}$. 3 cases had mild tricuspid regurge. 1 case had moderate tricuspid regurge. 1 case had severe tricuspid regurge. In group II, 2 patients had small residual VSD $(2 \mathrm{ml}) .2$ patients had residual pulmonary hypertension ranged between 25 and $60 \mathrm{mmHg}$. 1 case had mild tricuspid regurge. 2 patients had moderate tricuspid regurge. 1 case had severe tricuspid regurge.

\section{Discussion}

Persistent pulmonary hypertension, after ventricular septal defect was closed, was one of the most important causes of morbidity and death. (4)

This study consisted of 60 patients who were divided in three groups $(<3,3-6,6-12$ months), to determine the effect of the use of antihypertension drugs after the operation of ventricular, septal defect with pulmonary hypertension, and the age of these patients was 5-24 months with mean age $14 \pm 5.2$. (5)

Pulmonary hypertension is still a major predictor of perioperative morbidity and death in paediatric patients with left-to-right shunts. Sildenafil is an orally active PDE-5 inhibitor, induces vasodilation and has antiproliferative action across the pulmonary vasculature through the $\mathrm{NO} /$ cyclic guanosine monophosphate route. In 2011, EMA clearance for usage in children > 1 year old was obtained for sildenafil. (6)

In Egypt, pulmonary hypertension is still a major medical issue with congenital heart disease, since many instances of heart surgery centres that have substantial pulmonary hypertension are still encountered. This is because of the absence of regular medical exams.

We have split our patients into two groups to determine the impact of pulmonary antihypertensive medications. The mean PA pressure for the first group was $59.2 \pm 9.5$, with 30 patients without the medicine and the second group, the mean PA pressure was 66.4 \pm 9.1 , including 30 patients with the medication. In the research by SchulzeNeick and colleagues, in the first group the average pulmonary artery pressure was $20 \pm 5$ and $26 \pm 8$. (7)

Anna Hofer et colleagues examined 65 patients split into 2 groups and discovered, according to pulmonary hypertension response, ventilation time, ICU staying and hospitals, that there is no difference between 2 groups. In our research, we observed that the group receiving antihypertensive medications had significant reductions in lung pressure, ventilation, UCI and hospitalisation duration. (8)

Between 2002 and 2004, Farah Peiravian and her collaborators examined 45 patients, split into 2 categories, and observed a substantial reduction in the pulmonary postoperative pressure in the sildenafil group.(9)

In a retrospective investigation in VSD patients, Palma et al. demonstrated that sildenafil applied substantially reduced pulmonary and pulmonary/systemic arterial pressures following surgery. (10)

Hamid Bigdelian and Mohsen Sedighi reviewed clinical results of 63 children who were closed with VSD and were divided into two groups, concluding that PAS therapy in children with septal ventricular defects seems to be effective and safe to prevent postoperative PAH and pulmonary hypertension crises and has a positive effect on postoperative care and intubation reduction (11)

Many studies have shown that pulmonary hypertensive crisis is a significant risk factor for postoperative death after surgical closure in the literature in hypertensive VSD patients with various percentages.(12-14)

We observed a $16 \%$ incidence of pulmonary hypertensive crises between our first group and 10\% in our second group, which is greater than other authors such as Farah Peirvian et al. (9), who reported a 9.5\% incidence and less than Ingram and colleagues who reported a $20 \%$ incidence. 
The literature has been well recognised for the reduction of pulmonary artery pressures by oral sildenafil, which avoids a serious lung hypertension which causes hemodynamic instability and oxygen degradation accompanying a sudden rise in pulmonary or central venous pressure. In the current series, oral sildenafil were administered in the second group with pre-operative severe pulmonary hypertension in the immediate postoperative period when we anticipated pulmonary hypertensive crises and good outcomes in reducing pulmonary arterial pressure. Other findings have been based on the time and dosage of oral sildenafil in our research. (15)

Hopkins and colleagues 16 examined the impact of the postoperative pulmonary hypertensive crisis and found a $54.5 \%$ death rate among severely pulmonary hypertension patients. Lindberg and colleagues 17 also observed 22.2 percent mortality in their patients following pulmonary hypertensive crises. In our study, death was $11.6 \%$ among our patients who experienced a postoperative pulmonary hypertension crisis.

In spite of the recent progress in intraoperative and postoperative treatment in Egypt, the incidence of lung hypertensive crisis and death is still significant compared to the majority of other series of patients such as those with severe pulmonary hypertension reporting 7.4 percent.(8)

\section{Conclusion}

For postoperative pulmonary hypertension, sildenafil may be regarded an appealing and successful oral treatment. It is safe, easy to use and cheap. Further research are, however, required to establish the effectiveness, safety and optimum dosage of sildenafil in youngsters.

\section{References}

[1] P.Heck, A.Bambul, J.Eicken, P.KasnarSamprec, A.Ewert, and Hager. "Early Pulmonary Arterial Hypertension Immediately after Closure of a Ventricular or Complete Atrioventricular Septal Defect beyond 6 Months of Age." International Journal of Cardiology.vol.228,pp.313-18,2017.

[2] Fraser, D.Charles, Xun Zhou, Sandeep Palepu, Cecillia Lui, Alejandro Suarez-Pierre, Todd C. Crawford, J. Trent Magruder, et al. "Tricuspid Valve Detachment in Ventricular Septal Defect Closure Does Not Impact Valve Function.” The Annals of Thoracic Surgery.vol.106,pp.14550,2018 .

[3] Sasaki, Yuki, Tsukasa Ozawa, Hiroyuki Matsuura, Tsutomu Saji, Takeshiro Fujii, Yoshinori Watanabe, Noritsugu Shiono, Yoshinori Takanashi, and Nobuya Koyama. "Ventricular Septal Defect Repair in an Infant with Severe Pulmonary Hypertension and Preoperatively Diagnosed Left Ventricular Noncompaction." The Journal of Thoracic and Cardiovascular Surgery.vol.139, ,pp.3-33,2010.
[4] G.Palma, R.Giordano, V.Russolillo. Sildenafil therapy for pulmonary hypertension before and after pediatric congenital heart surgery. Tex Heart Inst J.vol. 38(3),pp.238-42,2011.

[5] Siyami Ersek. doi: 10.1111/jocs.12073, J Card Surg.vol. 28,pp.174-179,2013.

[6] VK.Sharma, S.Joshi, A.Joshi . Does intravenous sildenafil clinically ameliorate pulmonary hypertension during perioperative management of congenital heart diseases in children? A prospective randomized study. Ann Card Anaesth.vol. 18,pp.510-16, 2016.

[7] I.Schulze-Neick, J.Li, DJ.Penny and AN.Redington. Pulmonary vascular resistance after cardiopulmonary bypass in infants: Effect on postoperative recovery. J Thorac Cardiovasc Surg.vol.121,pp.1033-1039,2001.

[8] Hofer, Anna, Grohmann, Clemens, SamesDolzer, Eva, Meier, Hans. Prospective Randomised Study of Postoperative Prophylactic Application of Sildenafil After Pediatric Cardiac Surgery. Journal of Clinical \& Experimental Cardiology.vol.8,pp. 645$651,2015$.

[9] F.Peiravian, AA. Amirghofran, M.Borzouee, GH.Ajami, MR. Sabri, S. Kolaee. Oral sildenafil to control pulmonary hypertension after congenital heart surgery. Asian Cardiovasc Thorac Ann.vol.(2),pp.113-17, 2007.

[10] G.Palma, R.Giordano, V.Russolillo, S.Cioffi, S.Palumbo, M.Mucerino, V.Poli, C.Vosa. Sildenafil therapy for pulmonary hypertension before and after pediatric congenital heart surgery. Tex Heart Inst J.vol.38(3),pp.238-42 ,2011.

[11]Bigdelian H, Sedighi M. The role of preoperative sildenafil therapy in controlling of postoperative pulmonary hypertension in children with ventricular septal defects. J Cardiovasc Thorac Res.vol.9,pp.179-182,2017.

[12] L.Lindberg, AK.Olsson, P.Jögi and C.Jonmarker How common is severe pulmonary hypertension after pediatric cardiac surgery? J Thorac Cardiovasc Surg.vol.123,pp.1155-1163,2002.

[13] G.Palma, R.Giordano, V.Russolillo, S.Cioffi, S.Palumbo, M.Mucerino, V.Poli and C.Vosa Sildenafil therapy for pulmonary hypertension before and after pediatric congenital heart surgery. Tex Heart Inst J.vol.38(3),pp.23842,2011.

[14] RA.Hopkins, C.Bull, SG.Haworth, de MR.Leval and J.Stark Pulmonary hypertensive crises following surgery for congenital heart defects in young children. Eur J Cardiothorac Surg.vol.5,pp.628-34,1991.

[15] S.Nemoto, T.Sasaki, H.Ozawa, T.Katsumata, K.Kishi, K.Okumura, Y.Mori and O.Umegaki Oral sildenafil for persistent pulmonary hypertension early after congenital cardiac 
surgery in children. Eur J Cardiothorac Surg.vol.38,pp.71-77,2010.

[16] RA.Hopkins, C.Bull, SG.Haworth, de MR.Leval and J. StarkPulmonary hypertensive crises following surgery for congenital heart defects in young children. Eur J Cardiothorac Surg.vol.5,pp.628-34,1991.

[17] L.Lindberg, AK.Olsson, P.Jögi and C.Jonmarker How common is severe pulmonary hypertension after pediatric cardiac surgery? J Thorac Cardiovasc Surg.vol.123,pp.1155-1163,2002. 